\title{
Padronização de método analítico para avaliação do grau de exposição da fenilalanina em hidrolisados de caseína, por espectrofotometria derivada segunda
}

\author{
Cristiane Márcia da Silva Barbosa, Harriman Aley Morais, Viviane Dias Medeiros Silva, Mônica \\ Cristina de Oliveira, Marialice Pinto Coelho Silvestre*
}

Faculdade de Farmácia, Universidade Federal de Minas Gerais

*Correspondência:

M. P. C. Silvestre

Depto. De Alimentos

FAFAR - UFMG

Av. Olegário Maciel, 2360

Lourdes, 30180-112

Belo Horizonte - MG - Brasil

E-mail: malice@farmacia.ufmg.br
Hidrolisados protéicos com baixo teor ou isentos de fenilalanina (Phe) têm sido empregados em formulações para fenilcetonúricos. Várias condições de hidrólise enzimática têm sido propostas na literatura para promover a liberação de Phe e, assim, facilitar sua remoção posterior. Neste trabalho, a espectrofotometria derivada segunda (EDS), um método analítico rápido, simples e de custo relativamente baixo, foi utilizada, inicialmente, para a caracterização dos aminoácidos aromáticos e, em seguida, para a determinação do grau de exposição da Phe em diferentes hidrolisados de caseína, obtidos pela ação da papaína. Os resultados obtidos indicam que o hidrolisado preparado à temperatura de $37{ }^{\circ} \mathrm{C}$, relação enzima/substrato de 4\%, pH 7,5, foi o que apresentou o maior grau de exposição da Phe, sendo o mais indicado para a preparação de dietas para fenilcetonúricos. Com relação à caracterização dos aminoácidos aromáticos, o emprego da EDS permitiu a separação dos picos de tirosina (Tyr) e triptofano (Trp), em pH 13,0. Além disso, observou-se semelhança entre os espectros de derivada segunda das soluções contendo somente os aminoácidos aromáticos e dos hidrolisados de caseína.
Unitermos:

- Aminoácidos aromáticos

- Hidrolisados protéicos

- Espectrofotometria derivada segunda

- Fenilalanina

- Fenilcetonúria

\section{INTRODUÇÃO}

Hidrolisados protéicos têm sido usados em dietas para indivíduos que não podem ingerir proteínas intactas (Silvestre, 1997) e são, também, a base de suplementos dietéticos para diversas finalidades. A qualidade nutricional destes hidrolisados está relacionada aos seus conteúdos em peptídeos de baixo peso molecular, especialmente di- e tripeptídeos, visto que estes são absorvidos mais rapidamente do que aminoácidos livres (Silvestre et al., 1994; Shimamura et al., 1999). Além disso, apresentam menor osmolaridade, sendo melhor tolerados por in- divíduos com dificuldade de absorção (Furst et al., 1990; González-Tello et al., 1994).

No caso de fenilcetonúricos, a terapia nutricional consiste na restrição da ingestão de fenilalanina (Phe) ao mínimo requerido, empregando-se misturas de aminoácidos livres (Mahan, Arlin, 1994; Dutra de Oliveira, 1998) ou hidrolisados protéicos, contendo baixo teor deste aminoácido aromático (Tesmer et al., 1998). Várias condições de hidrólise enzimática têm sido propostas na literatura para promover a liberação de Phe e, assim, facilitar sua remoção posterior (Lopes-Bajonero et al., 1991; Moszczynski, Idiziak, 1993; Outinen et al., 1994). 
Os aminoácidos aromáticos (tirosina, triptofano e fenilalanina) apresentam bandas de absorção características na região do ultravioleta, entre 240 e $310 \mathrm{~nm}$ (Ichikawa, Terada, 1977; Cahill, Padera, 1980; Ichikawa, Terada, 1981; Miclo et al., 1995). A espectrofotometria derivada segunda (EDS) tem sido utilizada para separar o complexo espectro de absorção de proteínas nas contribuições individuais dos três aminoácidos aromáticos, sendo considerado um método simples, rápido e de custo relativamente baixo, para mostrar diferenças espectrais entre proteínas nativas e desnaturadas (Ragone et al., 1984).

A EDS pode também ser empregada para a quantificação de aminoácidos aromáticos nas misturas de aminoácidos livres. Entretanto, neste caso, este método apresenta algumas dificuldades devido à similaridade dos espectros da Tyr e do Trp, em pH 7,0 e à interferência que exercem sobre as fracas bandas de absorção da fenilalanina (Ichikawa, Terada, 1981; Miclo et al., 1995). Para solucionar este problema Ichikawa, Terada (1981) propuseram utilizar a EDS em $\mathrm{pH} 13,0$, uma vez que neste valor de $\mathrm{pH}$ o espectro da Tyr altera-se devido à dissociação de seu grupo $\mathrm{OH}$ fenólico, melhorando a definição dos picos de Tyr e Trp.

Com relação à análise de hidrolisados protéicos, a EDS foi empregada pela primeira vez por Silvestre et al. (1993), tendo se revelado como um método útil para se avaliar a pureza de hidrolisados comerciais, indicando a adição de aminoácidos livres, de proteínas nativas ou mesmo de hidrolisados com diferentes graus de hidrólise. Além disso, estes autores demonstraram que a intensidade dos picos, no espectro de derivada segunda de proteínas e peptídeos, está relacionada com a exposição dos aminoácidos aromáticos, sendo tanto maior quanto mais próximo o grupamento aromático estiver da posição C- ou N-terminal. Assim sendo, pensou-se neste trabalho em utilizar a EDS como método de triagem de hidrolisados protéicos, indicando as condições de reação que levaram à maior exposição da Phe. Estes preparados enzimáticos seriam os escolhidos para uma posterior remoção de Phe, visando ao preparo de formulações dietéticas para fenilcetonúricos. Foi realizado, inicialmente, um estudo aprofundado dos espectros de derivada segunda dos aminoácidos aromáticos, em pH 7,0 e 13,0e, em seguida, empregou-se a EDS para avaliar o grau de exposição de Phe em hidrolisados de caseína, obtidos pela ação da papaína.

\section{MATERIAL E MÉTODOS}

\section{Material}

Os aminoácidos L-fenilalanina (P2126), L-tirosina (T3754), L-triptofano (T0254) e a caseína bovina (C7078) foram adquiridos da Sigma Chemical Co. (St.Louis, MO,
EUA). A papaína foi gentilmente cedida pela BIOBRÁS (Montes Claros, MG, Brasil).

\section{Métodos}

\section{Preparo dos hidrolisados de caseína}

Foram preparados cinco hidrolisados protéicos. As soluções de caseína a $0,125 \%(\mathrm{p} / \mathrm{V})$ em tampão fosfato $0,01 \mathrm{~mol} / \mathrm{L}(\mathrm{pH} 6,5$ e 7,5) foram, inicialmente, préaquecidas em banho-maria, a $90{ }^{\circ} \mathrm{C}$, por $30 \mathrm{~min}$. Posteriormente, a temperatura foi ajustada para cada caso e a papaína foi adicionada numa dada concentração, de maneira a obter a relação enzima/substrato (E:S) desejada. O tempo total de hidrólise foi $5 \mathrm{~h}$. Os produtos assim obtidos foram liofilizados. Todos os parâmetros das reações estão apresentados na Tabela I.

TABELA I - Parâmetros hidrolíticos empregados no preparo dos hidrolisados de caseína pela papaína

\begin{tabular}{cccc}
\hline Hidrolisados & Temperatura $\left({ }^{\circ} \mathrm{C}\right)$ & $\mathrm{pH}$ & $\mathrm{E}: \mathrm{S}(\%)$ \\
\hline H1 & 37 & 7,5 & 4 \\
$\mathrm{H} 2$ & 37 & 7,5 & 2 \\
$\mathrm{H} 3$ & 40 & 7,5 & 4 \\
H4 & 37 & 6,5 & 4 \\
H5 & 60 & 7,5 & 4 \\
\hline
\end{tabular}

$\mathrm{E}: \mathrm{S}=$ relação enzima:substrato

\section{Padronização do método espectrofotométrico de derivada segunda}

- Preparo da mistura de Tyr e Trp na presença de Phe

Soluções estoques de Phe $\left(9,6 \times 10^{-5} \mathrm{~mol} / \mathrm{L}\right)$, Tyr $\left(7,0 \times 10^{-5} \mathrm{~mol} / \mathrm{L}\right)$ e $\operatorname{Trp}\left(1,3 \times 10^{-5} \mathrm{~mol} / \mathrm{L}\right)$ foram preparadas em tampão fosfato de potássio monobásico $0,01 \mathrm{~mol} / \mathrm{L}$, $\mathrm{pH} 13,0$. A partir de mistura contendo $10 \mathrm{~mL}$ de cada solução, foram feitas diluições sucessivas, de forma a se obter concentrações de Tyr na faixa de 4,23 a 21,2 x $10^{-6} \mathrm{~mol} / \mathrm{L}$, e de Trp, variando de 7,38 a $36,9 \times 10^{-7} \mathrm{~mol} / \mathrm{L}$.

- Preparo da mistura de Phe na presença de Tyr e Trp

Soluções estoques dos aminoácidos aromáticos foram preparadas em tampão fosfato de potássio monobásico $0,1 \mathrm{~mol} / \mathrm{L}$, pH 7,0, nas seguintes concentrações: Phe: $6,05 \times 10^{-4} \mathrm{~mol} / \mathrm{L}$; Tyr: $5,52 \times 10^{-4} \mathrm{~mol} / \mathrm{L}$ e Trp: $4,90 \times 10^{-4} \mathrm{~mol} / \mathrm{L}$. Em seguida, fez-se mistura com $10 \mathrm{~mL}$ de cada solução, a partir da qual foram feitas diluições 
sucessivas, de forma a se obter concentrações de Phe variando de 0,34 a $2,02 \times 10^{-4} \mathrm{~mol} / \mathrm{L}$.

- Leitura dos espectros

Foram feitas leituras de espectros de absorvância das misturas de aminoácidos aromáticos, preparadas de acordo com os itens anteriores (espectrofotômetro CECIL modelo CE2041, Buck Scientific, Inglaterra), na faixa de 250 a $280 \mathrm{~nm}$, para a Phe, e entre 250 a $350 \mathrm{~nm}$, para Tyr e Trp. Os espectros de derivada segunda foram traçados empregando-se um computador contendo software GRAMS-UV (Galactic Industries Corporation, Salem, NH, EUA), acoplado ao espectrofotômetro.

Avaliação da linearidade do método e aplicação aos diferentes hidrolisados protéicos

Para se traçar a curva padrão da Phe foram feitas leituras dos espectros das soluções de Phe na presença de Tyr e Trp. Foram traçadas oito curvas, duas para cada pico negativo ("a", "b", "c" e "d" - Figura 1B), empregando suas respectivas áreas ou alturas em função da concentração do aminoácido, sendo que a escolhida como curva padrão apresentou maior coeficiente de correlação.

Para a determinação do grau de exposição de Phe foram preparadas soluções dos diferentes hidrolisados de caseína a $0,08 \%(\mathrm{p} / \mathrm{V})$, em $\mathrm{pH} 7,0$. As leituras da absorvância foram feitas no mesmo intervalo de comprimento de onda utilizado para a curva padrão. Os valores das áreas ou alturas dos picos negativos no espectro de derivada segunda dos hidrolisados foram, então, levados à curva padrão da Phe e os resultados encontrados para as concentrações correspondem, então, ao grau de exposição de Phe dos hidrolisados de caseína, em mol/L.

\section{Análise estatística}

Todas as determinações foram realizadas em triplicata. Para a determinação das diferenças entre as médias das áreas ou alturas dos picos dos aminoácidos aromáticos entre os diferentes hidrolisados de caseína, foi feita a Análise de variância (ANOVA fator único) e o Teste de Duncan. Para se avaliar a linearidade da curva de calibração da Phe foi feita a análise de regressão (Gomes, 1990).

\section{RESULTADOS E DISCUSSÃO}

\section{Características do espectro de derivada segunda da Tyr e do Trp}

Os espectros de absorvância e de derivada segunda da Tyr e Trp, bem como os do hidrolisado H1, em pH 13,0, estão representados na Figura 1. Os valores máximos de absorvância para o Trp foram observados ao redor de 278, 287 e 297 nm, e os mínimos em 283 e 292 nm, sendo os picos negativos denominados pelas letras "a" e "b", respectivamente (Figura 1B). A Tyr caracterizou-se por uma banda larga ("c") compreendida entre 305 e 319 nm, com máximo próximo de $310 \mathrm{~nm}$, a qual, segundo Ichikawa, Terada (1981), corresponde à dissociação ácida do grupo $\mathrm{OH}$ fenólico deste aminoácido aromático, que ocorre em pH 13,0. Na Figura 1D, pode-se observar que o espectro de EDS do H1 apresenta perfil similar ao da mistura de aminoácidos.

De acordo com Ichikawa, Terada (1981), em pH 13,0 , as propriedades ópticas da Phe não têm qualquer efeito e aquelas da Tyr têm uma influência muito reduzida no espectro do Trp entre 286 e $300 \mathrm{~nm}$. Assim, a concentração de Trp em mistura de aminoácidos aromáticos pode ser determinada nesta faixa de comprimento de onda. Para a Tyr, esta determinação seria possível empregandose a banda ao redor de $310 \mathrm{~nm}$, visto que não há interferência da Phe, e a absorvância do Trp é muito pequena.

\section{Características do espectro de derivada segunda da Phe}

A título de exemplo, os espectros de absorvância e de derivada segunda da Phe, em mistura de aminoácidos aromáticos, e do hidrolisado $\mathrm{H} 1$, em $\mathrm{pH}$ 7,0, estão representados na Figura 2. Para a Phe, observa-se a presença de quatro picos negativos entre 250 e $280 \mathrm{~nm}$, com máximos situados em 253, 258, 263, 268 e $273 \mathrm{~nm}$, e mínimos em 257, 262, 267 e $272 \mathrm{~nm}$, sendo os picos delimitados por estes pontos denominados pelas letras "a", "b", "c" e "d", respectivamente (Figura 2B). O espectro de derivada segunda do $\mathrm{H} 1$ assemelha-se ao da Phe, com picos negativos situados em comprimentos de onda similares (Figura 2D). Esta semelhança entre os espectros de aminoácidos padrões e o de proteínas já havia sido relatada anteriormente por Ichikawa, Terada (1979), ao empregar a EDS para determinar a quantidade de resíduos de Phe em diversas proteínas desnaturadas ou em seus estados nativos (insulina, ribonuclease, lisozima e soro albumina).

Em outros trabalhos, a EDS foi utilizada com a mesma finalidade destes autores, mas os resultados obtidos diferem dos apresentados no presente trabalho, no que se refere ao número de picos negativos no espectro da Phe. Assim, Ichikawa, Terada (1977) obtiveram cinco picos negativos para este aminoácido, em $\mathrm{pH} 7,0$, enquanto que Miclo et al. (1995) relataram a presença de seis, em $\mathrm{pH}$ 1,9. Esta variação no espectro da Phe poderia estar asso- 

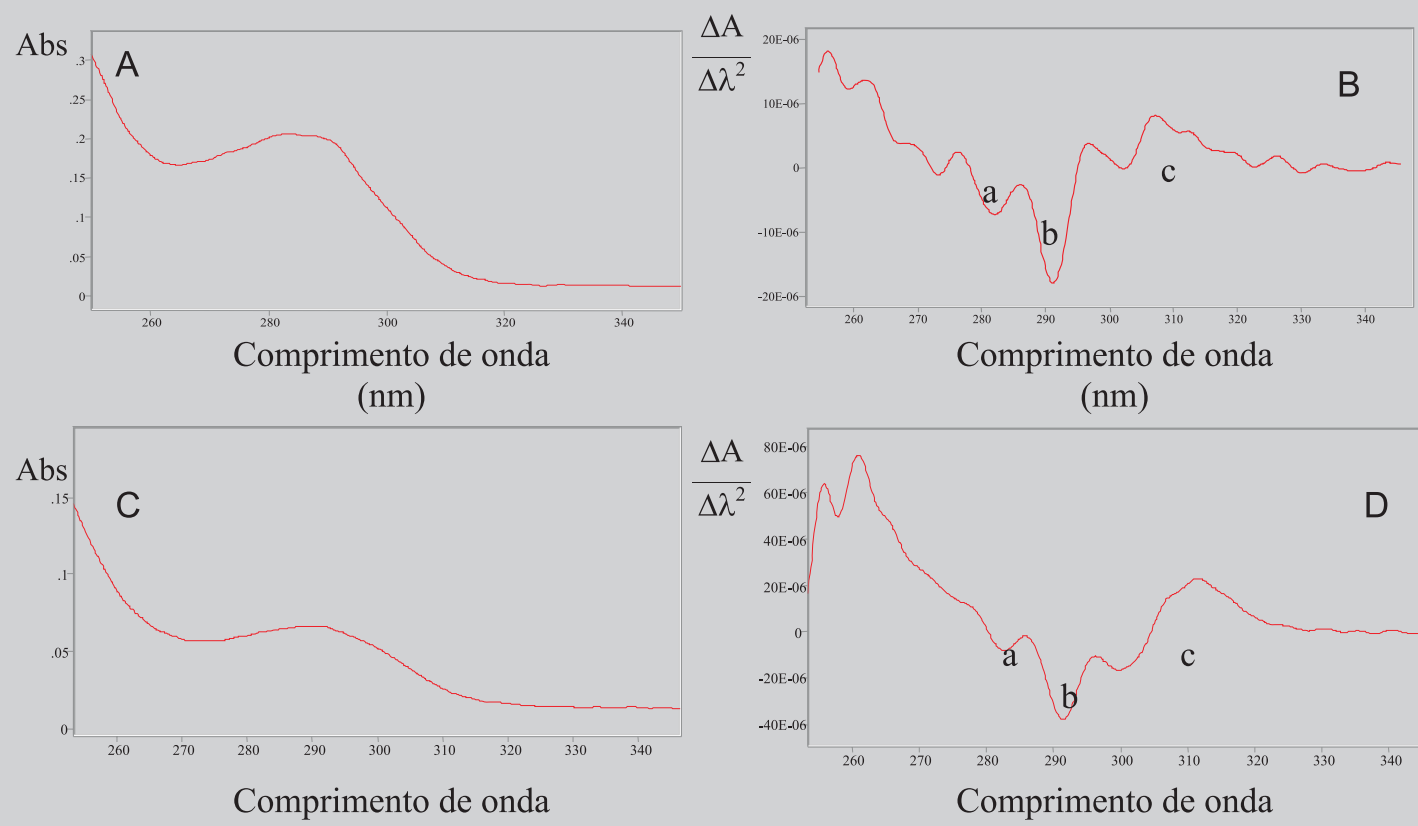

$(\mathrm{nm})$

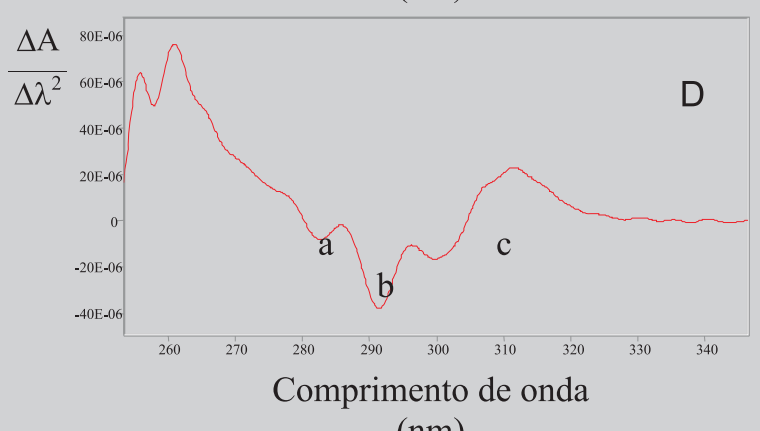

$(\mathrm{nm})$

FIGURA 1 - Espectros de absorvância (A) e de derivada segunda (B) de uma solução contendo Tyr (7,05 x 10-6 mol/L), $\operatorname{Trp}\left(1,23 \times 10^{-6} \mathrm{~mol} / \mathrm{L}\right)$ e Phe $\left(1,33 \times 10^{-5} \mathrm{~mol} / \mathrm{L}\right)$, e do hidrolisado H1 (C e D), em solução tampão fosfato de potássio monobásico, 0,01 mol/L, pH 13,0. (a, b): picos negativos do Trp; (c) banda positiva da Tyr.
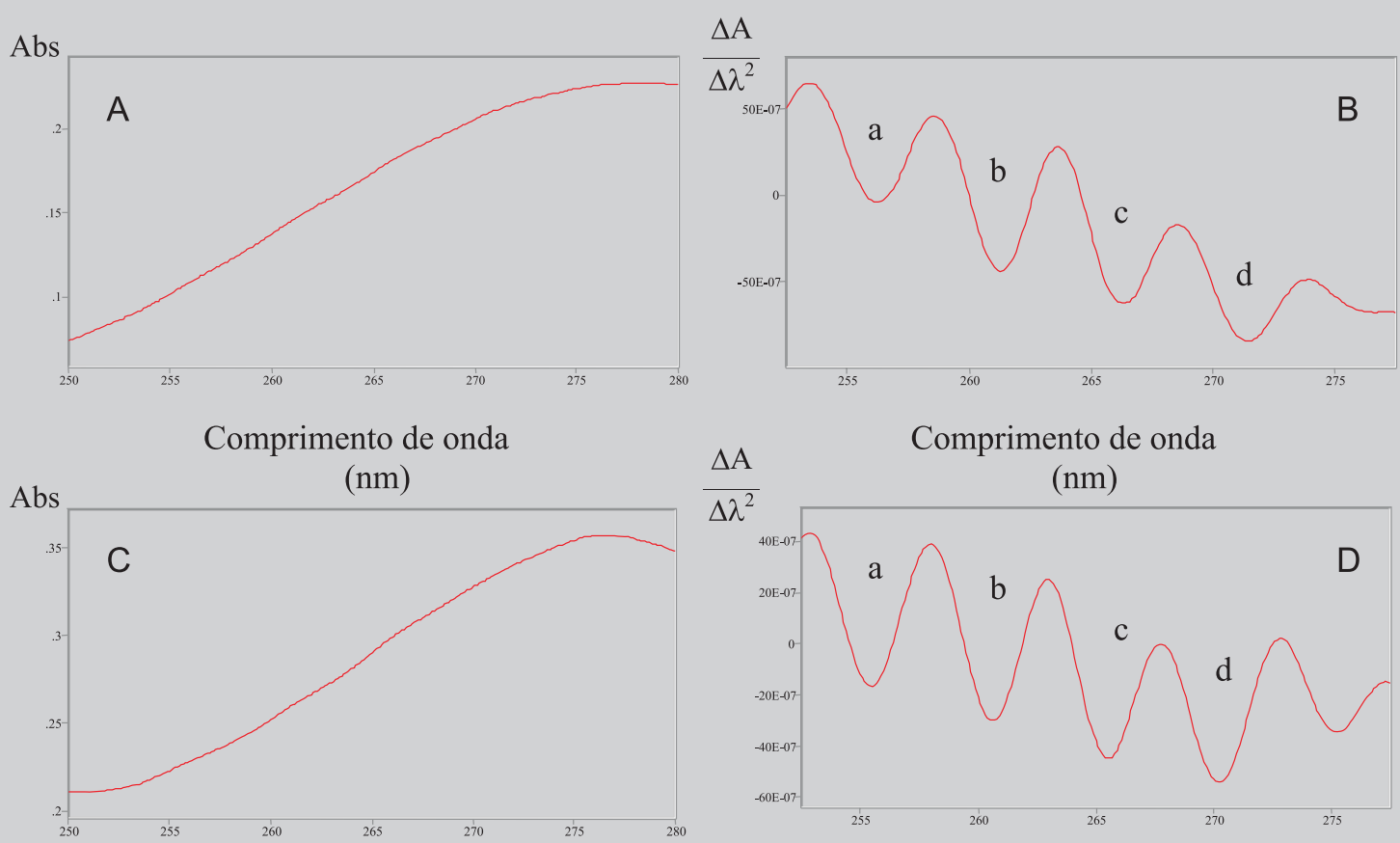

Comprimento de onda

$(\mathrm{nm})$

Comprimento de onda

$(\mathrm{nm})$

FIGURA 2 - Espectros de absorvância (A) e de derivada segunda (B) de uma solução contendo Tyr (6,1 x 10-5 mol/L), $\operatorname{Trp}\left(5,4 \times 10^{-5} \mathrm{~mol} / \mathrm{L}\right)$ e Phe $\left(6,7 \times 10^{-5} \mathrm{~mol} / \mathrm{L}\right)$ e do hidrolisado H1 (C e D), em solução tampão fosfato de potássio monobásico, 0,01 mol/L, pH 7,0. (a, b, c, d): picos negativos da Phe. 
ciada às diferenças nas formas utilizadas do aminoácido padrão (livre ou $N$-acetil-éster), na aparelhagem empregada, em especial o espectrofotometro e o software, como também no tipo de solvente e nos valores de $\mathrm{pH}$ (Levillain, Fompeydie, 1986; Fompeydie et al., 1989).

\section{Linearidade da curva padrão de Phe}

Na Figura 3, está apresentada a curva padrão para a Phe, na qual a área do pico "c" (Figura 2B) foi relacionada à concentração do aminoácido. Foi observado que se tratava de uma regressão linear, do tipo $\mathrm{Y}=\mathrm{ax}+\mathrm{b}$, sendo a equação da reta definida como $\mathrm{y}=1,6782 \mathrm{x}-0,0491$, com coeficiente de correlação próximo a $1(\mathrm{r}=0,9972)$.

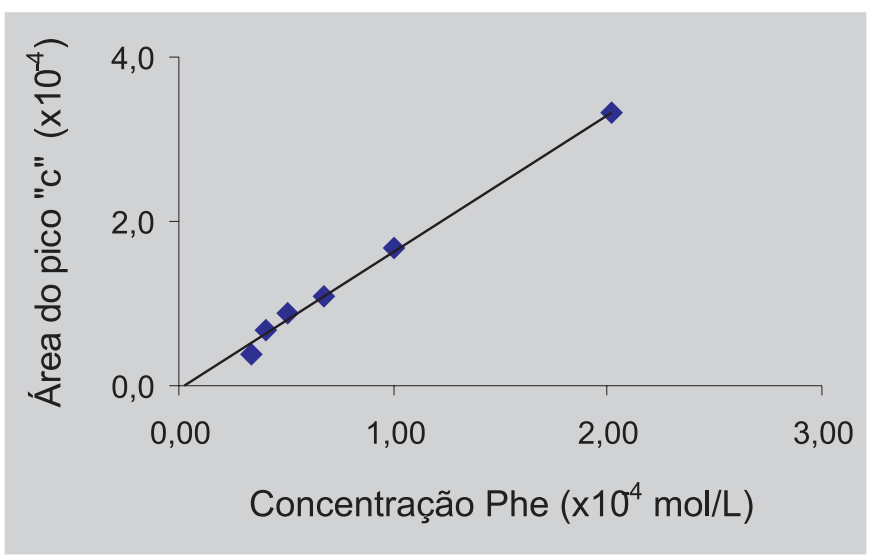

FIGURA 3 - Correlação entre a área do pico negativo "c" da Phe e a concentração do aminoácido $(0,34$ a 2,02 x $\left.10^{-4} \mathrm{~mol} / \mathrm{L}\right)$, em solução tampão fosfato de potássio monobásico, $0,01 \mathrm{~mol} / \mathrm{L}, \mathrm{pH} 7,0$. Os pontos representam a média de triplicata.

Observa-se, portanto, que houve boa linearidade para a Phe. Este resultado está de acordo com o obtido por Zhao et al. (1996), ao relacionar a altura do pico da Phe, em mistura com Trp e a Tyr, com a concentração do aminoácido. Ichikawa, Terada (1977) também obtiveram resultados semelhantes, com relação à Phe $(\mathrm{pH} 7,0)$, em presença de concentrações variadas de Tyr e Trp.

\section{Grau de exposição de Phe em hidrolisados protéicos}

Os valores da Tabela II servem para avaliar o grau de exposição de Phe pela hidrólise enzimática, uma vez que Silvestre et al. (1993) mostraram que a intensidade dos picos negativos dos aminoácidos aromáticos está relacionada a este parâmetro e não ao seu teor encontrado na proteína ou peptídeo. De fato, estes autores relataram que o "ambiente" envolvendo os grupos aromáticos afeta os seus espectros de derivada segunda e que a intensidade dos picos negativos é maior quanto mais próximo estes grupos estiverem da posição C- ou N-terminal. Estes resultados indicam que o hidrolisado $\mathrm{H} 1$ foi o que apresentou maior grau de exposição de Phe e, portanto, seria o escolhido dentre todas as condições de hidrólise estudadas para ser submetido a posterior remoção da Phe. Desta maneira, a EDS poderia servir como método de triagem de hidrolisados protéicos, visando ao preparo de dietas para fenilcetonúricos.

\section{AGRADECIMENTOS}

Os autores agradecem à CAPES, CNPq e FAPEMIG pelo apoio financeiro a este trabalho, na forma de bolsas de estudo ou de verba para a pesquisa.

\section{ABSTRACT \\ Standardization of analytical method to determination of phenylalanine exposure in casein hydrolysates by second derivative spectrophotometry}

Dietetic formulations for phenylketonurics generally contain free or low phenylalanine protein hydrolysates. Several hydrolytic conditions have been proposed in the literature to increase phenylalanine (Phe) exposure, in order to favor its subsequent removal. The second derivative spectrophotometry (SDS), a fast, simple and low cost analytical method, was used, in this work, for the determination of Phe exposure in different casein hydrolysates, prepared by using papain, and also for the

TABELA II - Grau de exposição da Phe nos hidrolisados de caseína

\begin{tabular}{|c|c|c|c|c|c|}
\hline Hidrolisado & $\mathrm{H} 1$ & $\mathrm{H} 2$ & $\mathrm{H} 3$ & $\mathrm{H} 4$ & $\mathrm{H} 5$ \\
\hline Concentração de Phe $\left(\mathrm{x} 10^{-4} \mathrm{~mol} / \mathrm{L}\right)$ & $1,71 \pm 0,40^{\mathrm{a}}$ & $0,89 \pm 0,08^{\mathrm{d}}$ & $1,02 \pm 0,18^{c}$ & $0,76 \pm 0,10^{\mathrm{e}}$ & $1,17 \pm 0,20^{b}$ \\
\hline
\end{tabular}


characteriztion of aromatic amino acids. A temperature of $37{ }^{\circ} \mathrm{C}$, an enzyme:substrate ratio of $4 \%$ and a $\mathrm{pH} 7.5$ showed to be the most suitable condition for preparing phenylketonuric diets, since they led to the highest Phe exposure. Concerning the characterization of aromatic amino acids, a good separation of tyrosine (Tyr) and tryptophan (Trp) peaks was obtained in pH 13.0, using the SDS. Moreover, the second derivative spectra of the aromatic amino acids were similar to those of the protein hydrolysates.

UNITERMS: Aromatic amino acid. Casein hydrolysate. Second derivative spectrophotometry. Phenylalanine. Phenylketonuria.

\section{REFERÊNCIAS BIBLIOGRÁFICAS}

CAHILL, J. E., PADERA, F. G. Derivative analysis of uv/ visible spectra. Am. Lab., Greens Farms, v. 12, n. 4, p. 101-112, 1980.

DUTRA-DE-OLIVEIRA, J. E. Ciências Nutricionais. São Paulo: Sarvier, 1998. 1328p.

FOMPEYDIE, D., IROLLO, P., LEVILLAIN, P. Spécial spectrophotométrie dérivée: huit spectromères au banc d'essai. Analysis, Oxford, v. 17, n. 10, p. 17-27, 1989.

FURST, P., ALBERS, S., STEHLE, P. Dipeptides in clinical nutrition. Proc. Nutr. Soc., New York, v.49, p.343-359, 1990.

GOMES, F. P. Curso de estatística experimental. 13. ed. Piracicaba: Nobel, 1990. 476p.

GONZÁLEZ-TELLO, P., CAMACHO, F., JURADO, E., PÁEZ, M. P., GUADIX, E. M. Enzymatic hydrolysis of whey proteins. II. Molecular - weight range. Biothecnol. Bioeng., New York, v.44, n. 4. p. 529-532, 1994.

ICHIKAWA, T., TERADA, H. Estimation of state and amount of phenylalanine residues in proteins by second derivative spectrophotometry. Biochim. Biophys. Acta, Amsterdam, v.580, p. 120-128, 1979.

ICHIKAWA, T., TERADA, H. Determination of phenylalanine, tryptophan and tyrosine in a mixture of amino acids by second derivative spectrophotometry. Chem. Pharm. Bull., Tokyo, v.29, n.2, p. 438-444, 1981.
ICHIKAWA, T., TERADA, H. Second derivative spectrophotometry as an effective tool for examining phenylalanine residues in proteins. Biochim. Biophys. Acta, Amsterdam , v. 494, p. 267-270, 1977.

LEVILLAIN, P., FOMPEYDIE, D. Spectrophotométrie dérivée: intérêt, limites et apllications. Analysis, Oxford, v. 14, n. 1, p. 1-20, 1986.

LOPES-BAJONERO, L. J., LARA-CALDERON, P., GALVEZ-MARISCAL， A., VELASQUEZARELLANO, A., LOPEZ-MUNGUIA, A. Enzimatic production of a low-phenilalanine product from skim milk powder and caseinate. J. Food Sci., Chicago, v. 56, n.4, p. 938-942, 1991.

MAHAN, L. K., ARLIN, M. T. Krause: Alimentos, Nutrição e Dietoterapia. 8. ed São Paulo: Rocca, 1994. 1052p.

MICLO, L. PERRIN, E.; DRIOU, A., MELLET, M., LINDEN, G. Determination of the ratios of the aromatic amino acids residues by first- or second-derivative UV spectrometry for a simple characterization of peptides. Int. J. Peptide Protein Res., Haguenau, v. 46, n.2, p. 186192, 1995.

MOSZCZYNSKI, P., IDZIAC, J. Preparation of enzimatic hidrolisates of casein depleted in phenilalanine. Appl. Biochem. Microbiol., New York, v. 29, n. 3, p. 302-306, 1993.

OUTINEN, M. T., TOSSAVAINEN, O., HARJU, M., LINKO, P. Method for removing phenilalanine from proteinaceous compositions, a product obtained and use thereof. Valio Oy, Helsink, Finland, Patents US 5547687, A23J3/34B4; A23J3/34C; A23L1/015E2; A61K38/01B; A61K38/01D6. 12 de setembro de 1994, 20 de agosto de 1994.

RAGONE, R., COLONNA, G., BALESTRIERI, C., SERVILLO, L., IRACE, G., Determination of tyrosine exposure in proteins by second derivative spectroscopy. Biochemistry, New York, v.23, p. 1871-1875, 1984.

SHIMAMURA, S., TAMURA, Y., MIYAKAWA, H., SAITO, H., KAWAGUCHI, Y., ISOMURA,N., AKAZOME, Y., OCHI, H., KAWAMOTO, M. Peptide mixture and products thereof. Morinaga Milk Industry Co., Ltd., Tokio, Japan, Patents US 5952193, A23C 21/ 02; A23C 21/04; A23C 21/06; A61K 38/01. 14 de abril de 1997, 14 de setembro de 1999. 
SILVESTRE, M. P. C. Review of methods for the analysis of protein hydrolysates. Food Chem., Washington, v.60, n.2, p.263-271, 1997.

SILVESTRE, M. P. C., DAUPHIN, C., HAMON, M. Application of UV absorbance and second-derivative spectrophotometry for analysing casein hydrolysates. Anal. Chim. Acta, Amsterdam, v. 282, p. 603-613, 1993.

SILVESTRE, M. P. C., HAMON, M., YVON, M. Analyses of protein hydrolysates. 1. Use of poly(2-hydroxyethylaspartamide)-silica column in size-exclusion chromatography for the fracionation of casein hydrolysates. J. Agric. Food Chem., Washington, v. 42, n. 12, p. 2778-2782, 1994.
TESMER, E., VETTER, M., RAFFLER, G., SCHWEIKHARDT, F. Process of making phenilalaninefree food for infants and small children. Milupa $\mathrm{GmbH} \&$ Co. KG, Friedrichsdorf, Germany, Patents US 1996000682627, A23L 1/305, A23L 1/304; 9 de setembro de 1996, 7 de abril de 1998 .

ZHAO, Q., SANNIER, F., GARREAU, I., LECOEUR, C., PIOT, J. M. Reversed-phase high-performance liquid chromatography coupled with second-order derivative spectroscopy for the quantitation of aromatic amino acids in peptides: application to hemorphins. J. Chromatog. A, Amsterdam, v. 723, p. 35-41, 1996.

Recebido para publicação em 28 de maio de 2001. 